\title{
Tensões Críticas de Flambagem Global de Almas de Vigas de Aço Enrijecidas Longitudinalmente
}

\author{
Denise Aparecida Barbosa ${ }^{1 *}$, Rodrigo Barreto Caldas ${ }^{2}$ e José Osvaldo Ferreira \\ Filho ${ }^{3}$ \\ ${ }^{1}$ Departamento de Engenharia de Estruturas, Universidade Federal de Minas \\ Gerais, denbarbosa@yahoo.com.br \\ 2 Departamento de Engenharia de Estruturas, Universidade Federal de Minas \\ Gerais, caldas@dees.ufmg.br \\ ${ }^{3}$ Departamento de Engenharia de Estruturas, Universidade Federal de Minas \\ Gerais, josefilho@ufmg.br
}

\section{Critical Global Stresses of Longitudinally Stiffened Webs of Steel Girders}

\begin{abstract}
Resumo
Este trabalho apresenta um estudo comparativo da tensão crítica de flambagem elástica global de almas de aço enrijecidas longitudinalmente, submetidas a tensões normais ou de cisalhamento. Para realização deste estudo foram analisadas almas enrijecidas com um ou dois enrijecedores longitudinais, utilizando a norma europeia EN 1993-1-5:2006 e o programa computacional EBPlate 2.01. Na obtenção das tensões críticas normais, a norma EN 1993-15:2006 apresenta valores inferiores aos obtidos no programa EBPlate $2.01 \mathrm{em}$ até $30 \%$, no caso de placa com enrijecedores flexíveis; entretanto, apresenta valores superiores em até $18 \%$, no caso de placa com enrijecedores rígidos. Na obtenção das tensões críticas de cisalhamento, a norma EN 1993-1-5:2006 fornece resultados inferiores em até $98 \%$ aos obtidos no programa EBPlate 2.01. Conclui-se que os resultados do programa EBPlate 2.01 possam representar melhor os valores de tensão crítica, uma vez que o Anexo A da norma EN 1993-1-5:2006 utiliza modelos analíticos simplificados e para casos específicos.
\end{abstract}

Palavras-chave: flambagem; alma enrijecida; viga esbelta.

\section{Abstract}

This work presents a comparative study of the critical elastic buckling stress in longitudinally stiffened steel webs subjected to direct or shear stresses. In order to carry out this study, stiffened webs with one or two longitudinal stiffeners were analyzed using the European standard EN 1993-1-5:2006 and the EBPlate 2.01 computer program. In order to obtain direct critical stresses, the EN 1993-1-5:2006 standard presents values lower than those obtained in the EBPlate 2.01 program by up to $30 \%$, in the case of plate with flexible stiffeners; however, it presents values higher up to $18 \%$, in the case of plate with rigid stiffeners. In obtaining the critical shear stresses, the EN 1993-1-5:2006 standard provides results of up to 98\% lower than those obtained in the EBPlate 2.01 program. It is concluded that the results of the EBPlate 2.01 program can better represent the critical stress values, since the Annex $A$ to the standard EN 1993-1-5:2006 uses simplified analytical models and for specific cases.

Keywords: buckling; stiffened web; slender girder. 


\section{Introdução}

Para a verificação de uma placa, segundo os modelos de cálculo previstos em normas como a EN 1993-1-5:2006, é necessária a determinação da tensão crítica de flambagem elástica global devido a tensões normais e/ou de cisalhamento, que é a tensão que torna instável uma placa ideal sem imperfeições e com comportamento elástico.

Para avaliar a capacidade resistente de uma placa enrijecida longitudinalmente submetida a tensões normais longitudinais, a norma EN 1993-1-5:2006 fornece modelos de cálculo da tensão crítica de flambagem elástica devido às tensões normais, para o comportamento Tipo Placa $\left(\sigma_{\mathrm{cr}, \mathrm{p}}\right)$ ou tensão crítica de flambagem global; e também para obter a tensão crítica de flambagem devido às tensões de cisalhamento $\left(\tau_{\mathrm{cr}}\right)$.

O Anexo A (A.1 - Nota 1) da EN 1993-1-5:2006 salienta que os valores das tensões críticas podem ser obtidos por gráficos apropriados, ou por simulações computacionais. Logo, considera-se importante avaliar as diferenças entre os resultados de tensões críticas devido as tensões normais ou de cisalhamento, obtidos pelos modelos de cálculo da norma EN 1993-1-5:2006 e o programa computacional para análise elástica de flambagem de placas, EBPlate 2.01.

Neste trabalho, serão estudadas almas de viga com seção transversal do tipo I com partes comprimidas e tracionadas, com um ou dois enrijecedores longitudinais de seção retangular sólida na parte comprimida.

\section{Procedimentos da Norma Europeia EN 1993-1-5:2006}

\subsection{Tensão crítica de flambagem elástica devido às tensões normais}

A determinação do coeficiente de flambagem $\left(\mathrm{k}_{\sigma}\right)$ para placa enrijecida longitudinalmente depende não somente da razão de aspecto $(\alpha)$ e condições de apoio, mas também de outros parâmetros, como as propriedades de rigidez axial, à flexão e à torção relativas da seção transversal dos enrijecedores (são chamadas relativas porque são comparadas às propriedades similares da placa isolada) e as posições dos enrijecedores.

Os coeficientes de flambagem e as tensões críticas de flambagem elástica obtidos pela norma EN 1993-1-5:2006 assumem que: 
a) os enrijecedores transversais são considerados rígidos, logo esta norma não contempla enrijecedores flexíveis;

b) os enrijecedores longitudinais não são considerados Classe 4, dessa forma, nenhuma redução devido à flambagem local é considerada;

c) a rigidez à torção dos enrijecedores longitudinais é considerada nula, assim, a falha associada à flambagem por torção dos enrijecedores longitudinais é prevista de forma conservadora;

d) os painéis não têm aberturas.

Para avaliar a capacidade resistente de uma placa enrijecida longitudinalmente submetida a tensões normais longitudinais, a norma EN 1993-1-5:2006 diferencia dois tipos de comportamento, sendo comportamento Tipo Placa e Tipo Pilar, no entanto ambos devem ser considerados. Neste trabalho, será estudado somente o comportamento Tipo Placa.

\subsubsection{Comportamento Tipo Placa}

A verificação do comportamento Tipo Placa, conforme a EN 1993-1-5:2006 requer o cálculo da denominada tensão crítica de flambagem elástica para o comportamento Tipo Placa, ou tensão crítica de flambagem global $\left(\sigma_{\mathrm{cr}, \mathrm{p}}\right)$. Esta é a tensão crítica associada com o modo de flambagem Tipo Placa que corresponde ao modo no qual a flambagem local, ou seja, dos subpainéis, não é avaliada. Este modo pode ser considerado como o resultado da flexão dos enrijecedores fora do plano da placa.

Para a determinação desta tensão crítica de flambagem elástica para placas enrijecidas, o Anexo A da EN 1993-1-5:2006 fornece dois modelos de cálculo de acordo com o número de enrijecedores longitudinais posicionados na parte comprimida da placa:

a) placa com um ou dois enrijecedores longitudinais na parte comprimida e demais enrijecedores na parte tracionada;

b) placa com pelo menos três enrijecedores longitudinais comprimidos, iguais e igualmente espaçados, caso no qual é denominado de múltiplos enrijecedores. 
Desta forma, a norma fornece fórmulas para casos específicos, porém não sugere um modelo geral, isto é, para qualquer que seja o número e a localização dos enrijecedores longitudinais.

Neste trabalho, serão estudadas almas de vigas do tipo I com partes comprimidas e tracionadas, com um ou dois enrijecedores individuais na parte comprimida.

\subsubsection{Rigidez à flexão relativa dos enrijecedores longitudinais}

A rigidez à flexão relativa dos enrijecedores longitudinais é dada pela Equação (2.1):

$$
\gamma=\frac{\mathrm{I}_{\mathrm{sl}}}{\mathrm{I}_{\mathrm{p}}}
$$

onde, $\mathrm{I}_{\mathrm{sl}}$ é o momento de inércia do painel enrijecido (placa e enrijecedores longitudinais); $I_{p}$ é o momento de inércia da placa isolada (desconsiderando os enrijecedores longitudinais), para flexão fora do plano, dado pela Equação (2.2):

$$
I_{p}=\frac{b t^{3}}{12\left(1-v^{2}\right)}=\frac{b t^{3}}{10,92}
$$

onde, t é a espessura da alma e, b é a altura da alma.

Para um valor de rigidez à flexão relativa denominada ótima $\left(\gamma^{*}\right)$ o enrijecedor longitudinal tem rigidez suficiente para permanecer reto e não flexionar fora do plano, juntamente com a placa, logo o modo correspondente é de flambagem local para cada subpainel da placa enrijecida. Portanto, para valores de rigidez à flexão relativa $\gamma<\gamma^{*}$, que corresponde a enrijecedor flexível, o modo resultante é de flambagem global, no qual o enrijecedor flexiona fora do plano, juntamente com a placa, ou seja, a tensão crítica "natural" (primeiro modo) de flambagem da placa corresponde à tensão crítica de flambagem global, isto considerando que os enrijecedores são posicionados em função da distribuição das tensões normais longitudinais de compressão.

Sendo assim, para valores de rigidez à flexão relativa $\gamma>\gamma^{*}$, que corresponde a enrijecedor rígido, a tensão crítica "natural" (primeiro modo) de flambagem da placa permanece constante e igual à tensão crítica de flambagem local, ou seja, de cada subpainel da placa enrijecida. Portanto, no caso de placa com enrijecedor rígido, a tensão crítica de flambagem global é obtida de maneira forçada, ou seja, não avaliando a flambagem local (dos subpainéis). 
O valor de $\gamma^{*}$ depende da razão de aspecto $(\alpha)$ e da rigidez axial relativa $(\delta)$, e pode ser obtido utilizando as fórmulas encontradas em Skaloud (1983) para as configurações mais comuns de almas enrijecidas.

\subsubsection{Procedimento para placa com um ou dois enrijecedores longitudinais na parte comprimida, conforme o Anexo A (A.2) da norma EN 1993-1-5:2006}

No caso de uma placa enrijecida longitudinalmente por um ou dois enrijecedores e uma distribuição não uniforme de tensões normais (tal como ocorre normalmente em uma alma de uma viga do tipo I ou caixão) a EN 1993-1-5:2006 apresenta um procedimento simplificado em seu Anexo A (A.1) - Placa Ortotrópica Equivalente para determinar a tensão crítica de flambagem elástica para uma placa simplesmente apoiada em todas as bordas. Esse modelo conhecido como Método do Pilar Fictício baseia-se em substituir a placa enrijecida por um pilar equivalente fictício restringido por um apoio contínuo elástico (no caso, a placa).

Portanto, a tensão crítica de flambagem elástica de placa $\left(\sigma_{\mathrm{cr}, \mathrm{p}}\right)$ é obtida a partir da tensão crítica elástica deste pilar equivalente $\left(\sigma_{\mathrm{cr}, \mathrm{sl}}\right)$. A área da seção transversal bruta do pilar equivalente $\left(\mathrm{A}_{\mathrm{sl}, 1}\right)$ é composta pela área bruta da seção transversal do enrijecedor mais próximo à borda com a maior tensão de compressão mais as partes adjacentes de contribuição da placa (Figura 1).

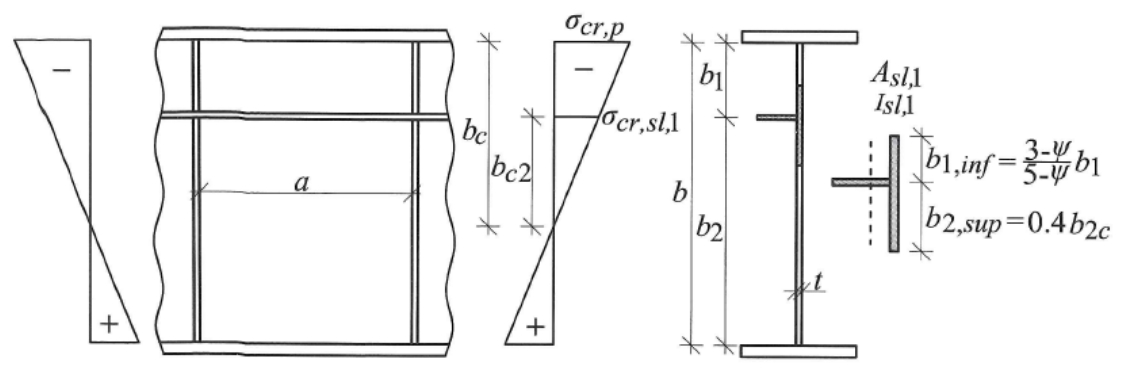

Figura 1 - Alma com um único enrijecedor longitudinal na parte comprimida (EN 1993-1-5, 2006, modificado).

A base deste modelo simplificado corresponde à flambagem deste pilar supondo-o como carregado axialmente e continuamente apoiado em uma base elástica, que representa a rigidez à flexão da placa. Essa base elástica considera os efeitos estabilizadores causados pela flexão da placa na direção perpendicular ao enrijecedor, quando este é submetido à compressão e tende a flambar. 
A tensão crítica de flambagem elástica do pilar equivalente é dada pelas Equações (2.3) ou (2.4):

$$
\sigma_{\mathrm{cr}, \mathrm{sl}}=\frac{1,05 \mathrm{E}}{\mathrm{A}_{\mathrm{sl}, 1}} \frac{\sqrt{\mathrm{I}_{\mathrm{sl}, 1} \mathrm{t}^{3} \mathrm{~b}}}{\mathrm{~b}_{1} \mathrm{~b}_{2}} \text { se } \mathrm{a} \geq \mathrm{a}_{\mathrm{c}}
$$

ou,

$$
\sigma_{\mathrm{cr}, \mathrm{sl}}=\frac{\pi^{2} \mathrm{EI}_{\mathrm{sl}, 1}}{\mathrm{~A}_{\mathrm{sl}, 1} \mathrm{a}^{2}}+\frac{\mathrm{Et}^{3} \mathrm{ba}^{2}}{4 \pi^{2}\left(1-v^{2}\right) \mathrm{A}_{\mathrm{sl}, 1} \mathrm{~b}_{1}{ }^{2} \mathrm{~b}_{2}{ }^{2}} \text { se } \mathrm{a}<\mathrm{a}_{\mathrm{c}}
$$

onde, $A_{s l, 1}$ é a área bruta do pilar equivalente; $I_{s l, 1}$ é o momento de inércia da seção bruta do pilar equivalente, em torno de um eixo centroidal e paralelo ao plano da placa; $\mathrm{b}_{1}, \mathrm{~b}_{2}$ são as distâncias entre as bordas longitudinais da alma e o enrijecedor longitudinal; $b$ é a soma de $b_{1} \operatorname{com~} b_{2} ; a_{c}$ é o comprimento de flambagem; a é o comprimento do painel.

Para obter a tensão crítica de flambagem elástica de placa $\left(\sigma_{\mathrm{cr}, \mathrm{p}}\right)$ definida como a maior tensão de compressão na placa, no caso de uma tensão gradiente sobre a largura da placa, deve-se extrapolar a tensão crítica obtida no pilar equivalente $\left(\sigma_{\mathrm{cr}, \mathrm{sl}}\right)$ na posição do enrijecedor comprimido para a borda mais comprimida da placa, conforme representado na Equação (2.5):

$$
\sigma_{\mathrm{cr}, \mathrm{p}}=\frac{\mathrm{b}_{\mathrm{c}}}{\mathrm{b}_{\mathrm{c} 2}} \sigma_{\mathrm{cr}, \mathrm{sl}}
$$

onde, $b_{c}$ e $b_{c 2}$ são valores geométricos da distribuição de tensões usados para $a$ extrapolação, conforme a Figura 1.

No caso de uma placa enrijecida com dois enrijecedores longitudinais posicionados na parte comprimida, a tensão crítica de flambagem elástica para placa simplesmente apoiada em todas as bordas $\left(\sigma_{\mathrm{cr}, \mathrm{p}}\right)$ é determinada com o mesmo procedimento usado para o caso de um único enrijecedor na parte comprimida. Porém, este procedimento deve ser repetido três vezes, e a tensão crítica será dada pelo menor valor dentre os obtidos para os três casos, conforme descrito a seguir e ilustrado na Figura 2:

a) o enrijecedor I é considerado como um pilar em base elástica contínua representando a placa, e assume-se que o enrijecedor II atua como um apoio rígido; 
b) o enrijecedor Il é considerado como um pilar em base elástica contínua fornecida pela placa, e assume-se que o enrijecedor I atua como um apoio rígido;

c) um enrijecedor único fictício equivalente aos enrijecedores I e II é considerado para simular a flambagem de ambos os enrijecedores simultaneamente.

O enrijecedor fictício equivalente é posicionado no ponto de aplicação da resultante das forças nos enrijecedores individuais I e II, conforme ilustra a Figura 2 e informa a Equação (2.6).

$$
\mathrm{b}_{1}^{\mathrm{I}+\mathrm{II}}=\frac{\mathrm{A}_{\mathrm{sl}, 2} \mathrm{~b}_{\mathrm{c}, 2}}{\mathrm{~A}_{\mathrm{sl}, 1} \mathrm{~b}_{\mathrm{c}, 1}+\mathrm{A}_{\mathrm{sl}, 2} \mathrm{~b}_{\mathrm{c}, 2}} \mathrm{~b}_{2}^{\mathrm{I}}+\mathrm{b}_{1}^{\mathrm{I}}
$$

onde, $A_{s l, 1}$ é a área da seção do enrijecedor I mais as partes adjacentes de contribuição da placa; $b_{c, 1}$ é a distância entre a linha neutra da alma e o enrijecedor I; $A_{s l, 2}$ é a área da seção do enrijecedor II mais as partes adjacentes de contribuição da placa; $b_{c, 2}$ é a distância entre a linha neutra da alma e o enrijecedor II; $b_{1}^{I}$ é a posição do enrijecedor I; $b_{2}^{I}$ é a posição do enrijecedor II.

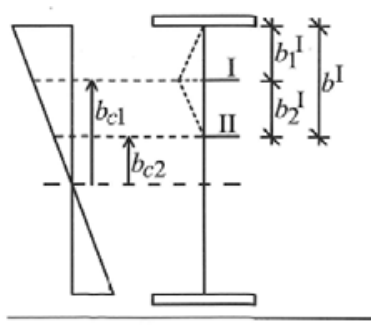

Enrijecedor I

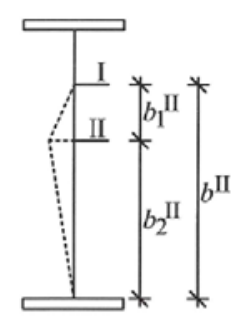

Enrijecedor II

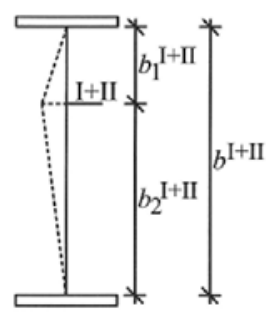

Enrijecedor equivalente

Figura 2 - Modelo com dois enrijecedores longitudinais na parte comprimida (EN 1993-1-5, 2006, modificado).

Como este enrijecedor substitui ambos os enrijecedores I e II, as propriedades da sua seção transversal são a soma das propriedades dos enrijecedores individuais. Neste modelo os enrijecedores posicionados na parte tracionada são desprezados.

\subsection{Tensão crítica de flambagem elástica devido às tensões de cisalhamento}

As tensões críticas de cisalhamento $\left(\tau_{\mathrm{cr}}\right)$ são obtidas através dos coeficientes de flambagem, $\mathrm{k}_{\tau}$, sendo dadas por $\tau_{\mathrm{cr}}=\mathrm{k}_{\tau} \sigma_{\mathrm{E}}$, onde $\sigma_{\mathrm{E}}$ é a tensão de referência, que é a tensão de flambagem de Euler com a rigidez à flexão de barra substituída pela rigidez 
de placa. O Anexo A (A.3) da norma EN 1993-1-5:2006 fornece as fórmulas para o cálculo do coeficiente de flambagem por cisalhamento de placa, sendo que:

a) para painéis sem enrijecedores longitudinais tais como subpainéis de painéis enrijecidos, ou para painéis somente com enrijecedores transversais rígidos (assumindo as bordas simplesmente apoiadas), têm-se as Equações (2.7) e (2.8):

$$
\mathrm{k}_{\tau}=4,00+5,34\left(\frac{\mathrm{h}_{\mathrm{w}}}{\mathrm{a}}\right)^{2} \quad \text { para } \frac{\mathrm{a}}{\mathrm{h}_{\mathrm{w}}}<1,0
$$

ou,

$$
\mathrm{k}_{\tau}=5,34+4,00\left(\frac{\mathrm{h}_{\mathrm{w}}}{\mathrm{a}}\right)^{2} \quad \text { para } \quad \frac{\mathrm{a}}{\mathrm{h}_{\mathrm{w}}} \geq 1,0
$$

onde, $\mathrm{h}_{\mathrm{w}}$ é a largura do painel, no caso, a altura da alma do perfil; a é o comprimento do painel, ou seja, a distância entre os enrijecedores transversais rígidos.

b) para painéis enrijecidos com um ou dois enrijecedores longitudinais, e razão de aspecto $\alpha<3$, tem-se a Equação (2.9):

$$
\mathrm{k}_{\tau}=4,1+\frac{6,3+0,18\left(\frac{\mathrm{I}_{\mathrm{sl}}}{\mathrm{t}^{3} \cdot \mathrm{h}_{\mathrm{w}}}\right)}{\alpha^{2}}+2,2 \sqrt[3]{\frac{\mathrm{I}_{\mathrm{sl}}}{\mathrm{t}^{3} \mathrm{~h}_{\mathrm{w}}}}
$$

onde, $\mathrm{I}_{\mathrm{sl}}$ é o momento de inércia para a flambagem perpendicular ao plano da placa, sendo determinado com o enrijecedor mais uma largura efetiva da placa, de 15\&t, em cada lado do enrijecedor, até à largura geométrica máxima existente sem partes sobrepostas, conforme a Figura 3.
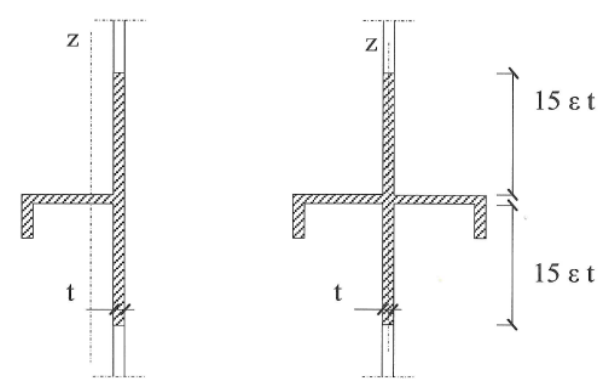

Figura 3 - Enrijecedor mais a largura efetiva da placa (JOHANSSON et al., 2007, modificado). 
c) para painéis enrijecidos com enrijecedores transversais rígidos e, um ou dois enrijecedores longitudinais, e razão de aspecto $\alpha \geq 3$; ou para painéis enrijecidos com mais do que dois enrijecedores longitudinais, tem-se as Equações (2.10) a (2.12):

$$
\mathrm{k}_{\tau}=4+5,34\left(\frac{\mathrm{h}_{\mathrm{w}}}{\mathrm{a}}\right)^{2}+\mathrm{k}_{\mathrm{\tau sl}} \text { para } \frac{\mathrm{a}}{\mathrm{h}_{\mathrm{w}}}<1,0
$$

ou,

onde:

$$
\mathrm{k}_{\tau}=5,34+4\left(\frac{\mathrm{h}_{\mathrm{w}}}{\mathrm{a}}\right)^{2}+\mathrm{k}_{\tau \mathrm{sl}} \text { para } \frac{\mathrm{a}}{\mathrm{h}_{\mathrm{w}}} \geq 1,0
$$

$$
\mathrm{k}_{\text {tsl }}=9\left(\frac{\mathrm{h}_{\mathrm{w}}}{\mathrm{a}}\right)^{2} \sqrt[4]{\left(\frac{\mathrm{I}_{\mathrm{sl}}}{\mathrm{t}^{3} \mathrm{~h}_{\mathrm{w}}}\right)^{3}} \geq \frac{2,1}{\mathrm{t}} \sqrt[3]{\frac{\mathrm{I}_{\mathrm{sl}}}{\mathrm{h}_{\mathrm{w}}}}
$$

As notas 3 e 5 do item 5.3 da EN 1993-1-5:2006 fornecem esquemas de verificação para enrijecedores transversais intermediários flexíveis.

\section{Programa computacional para análise elástica de flambagem de placas, EBPlate 2.01}

O programa EBPlate 2.01, Elastic Buckling of Plates, foi escrito em linguagem Visual Basic (VB) para o sistema Windows. O EBPlate 2.01 apresenta os modos de flambagem e calcula as tensões críticas correspondentes de flambagem elástica de placas retangulares com várias condições de contorno, espessura uniforme, carregadas no seu plano e com comportamento isotrópico ou ortotrópico. Também, o programa considera placas com enrijecedores longitudinais (seções abertas ou fechadas) e/ou transversais, ou placas não enrijecidas.

\subsection{Modelo para cálculo das tensões críticas}

No EBPlate 2.01, as tensões normais são interpoladas linearmente, a partir dos valores fornecidos para as bordas da placa. O cisalhamento é suposto como constante ao longo de toda a placa. O processo de cálculo é dividido em três etapas: a preparação das matrizes, a resolução do problema de autovetores e autovalores, e o cálculo das linhas de contorno que definem os modos de flambagem. 
O usuário fornece os parâmetros da forma deformada (parâmetros de Fourier) especificando o número máximo de meia ondas do modo de flambagem para cada direção da placa, o que indica a complexidade do modo de flambagem.

Conforme Galéa e Martin (2006), o programa EBPlate 2.01 calcula o fator crítico $\left(\phi_{\mathrm{cr}}\right)$, por meio de uma solução aproximada pelo método de energia semi-analítico de Rayleigh-Ritz. Este fator é tal que ao ser aplicado às tensões $\sigma_{x}, \sigma_{y}$ e $\tau$, definidas pelo usuário e que atuam na placa, resulta na tensão de flambagem elástica da placa. Logo, as tensões críticas são dadas pelas Equações (3.1) e (3.2):

$$
\sigma_{\mathrm{x}, \mathrm{cr}}=\phi_{\mathrm{cr}} \sigma_{\mathrm{x}} ; \sigma_{\mathrm{y}, \mathrm{cr}}=\phi_{\mathrm{cr}} \sigma_{\mathrm{y}}
$$

e,

$$
\tau_{\mathrm{cr}}=\phi_{\mathrm{cr}} \tau
$$

onde, $\phi_{\mathrm{cr}}$ é o fator crítico.

O programa fornece como resultados também os valores dos coeficientes de flambagem $\left(\mathrm{k}_{\sigma \mathrm{x}}, \mathrm{k}_{\sigma \mathrm{y}}, \mathrm{k}_{\tau}\right)$. As tensões críticas, obtidas através dos coeficientes de flambagem, são dadas pelas Equações (3.3) e (3.4):

$$
\sigma_{\mathrm{x}, \mathrm{cr}}=\mathrm{k}_{\sigma \mathrm{x}} \sigma_{\mathrm{E}} ; \sigma_{\mathrm{y}, \mathrm{cr}}=\mathrm{k}_{\sigma \mathrm{y}} \sigma_{\mathrm{E}}
$$

e,

$$
\tau_{\mathrm{cr}}=\mathrm{k}_{\tau} \sigma_{\mathrm{E}}
$$

O procedimento comum do usuário no EBPlate 2.01 consiste na avaliação dos modos de flambagem e escolha do modo global com o mínimo valor de $\phi_{\mathrm{cr}}$, o qual corresponde ao comportamento Tipo Placa; e em seguida no cálculo da tensão crítica de flambagem de placa.

Segundo Beg et al. (2010), normalmente para placas com enrijecedores "mais rígidos", modos globais são muito difíceis de serem calculados devido ao grande número de modos locais (a flambagem local dos subpainéis predomina). O cálculo da tensão de flambagem de placa por meio de análises de modos de flambagem leva a um problema sem solução quando os enrijecedores são "mais rígidos". Por esta razão, foi proposto um procedimento no EBPlate 2.01 para obter já no primeiro modo, a tensão crítica elástica correspondente ao comportamento Tipo Placa $\left(\sigma_{\mathrm{cr}, \mathrm{p}}\right)$. Usando o Procedimento 
Proposto no EBPlate 2.01, o modo de flambagem global de placa pode ser facilmente obtido.

Portanto, o cálculo da tensão crítica elástica para o comportamento Tipo Placa $\left(\sigma_{\mathrm{cr}, \mathrm{p}}\right)$ usando o programa EBPlate 2.01, pode ser realizado de duas maneiras:

a) método Convencional (procedimento usual) que consiste na avaliação dos modos de flambagem para o cálculo da tensão crítica;

b) procedimento Proposto no EBPlate 2.01.

\subsection{Procedimento Proposto no EBPlate 2.01 (2007)}

Um procedimento utilizando o programa EBPlate 2.01 foi desenvolvido durante o estudo realizado pelo Centre Technique Industriel de la Construction Metallique (CTICM), sendo calibrado com resultados numéricos obtidos pelo Método dos Elementos Finitos utilizando o programa ANSYS e comparado com as fórmulas do Anexo A da EN 1993-15:2006. Este procedimento é aplicável ao caso de placas submetidas às tensões normais longitudinais, com enrijecedores longitudinais independentemente da sua quantidade e localização, sendo o seu princípio apresentado na Figura 4. Este procedimento foi desenvolvido com o propósito de obter o valor da tensão crítica da placa enrijecida longitudinalmente para o comportamento do Tipo Placa $\left(\sigma_{\mathrm{cr}, \mathrm{p}}\right)$ definida como a primeira tensão crítica que fornece a flambagem dos enrijecedores longitudinais no contínuo elástico da placa com todas as flambagens locais dos subpainéis sendo evitadas.

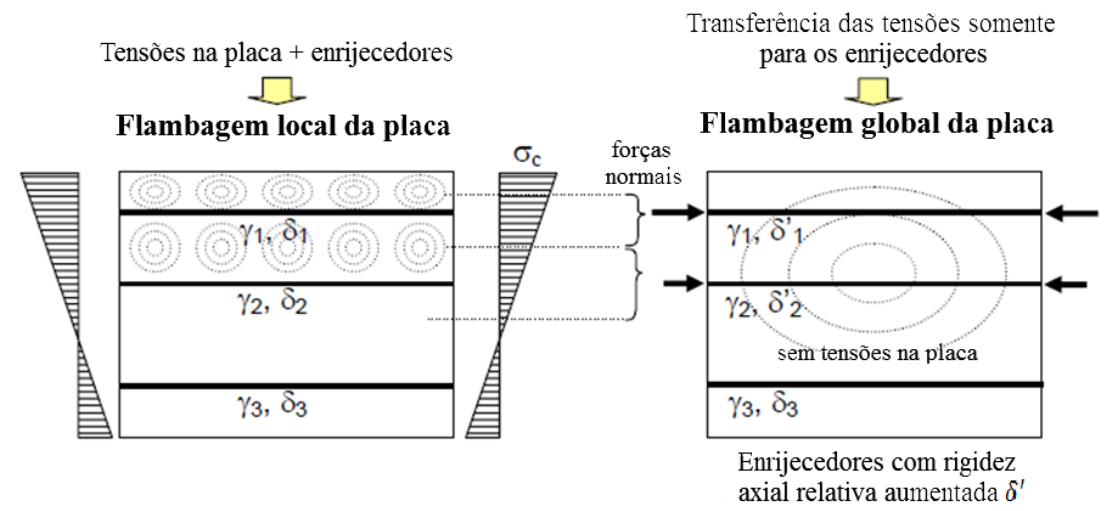

Figura 4 - Princípio do método (GALÉA e MARTIN, 2006, modificado).

Conforme Galéa e Martin (2006), o procedimento consiste em evitar a instabilidade local nos subpainéis, sem desprezar os efeitos desestabilizadores das tensões na própria 
placa, por meio do recurso de "transferência" dessas tensões para os enrijecedores. As tensões são "transferidas" da placa para os enrijecedores pela modificação da rigidez axial relativa de cada enrijecedor longitudinal na parte comprimida. Os autores apresentam as operações que os usuários devem realizar no programa EBPlate 2.01 para que esta "transferência" seja efetivada:

a) exclusão de todas as tensões longitudinais na própria placa, para que a flambagem local nos subpainéis não ocorra;

b) transferência das tensões da placa para os enrijecedores, por meio do recurso de aumentar a rigidez axial relativa da seção do enrijecedor longitudinal (parâmetro $\delta$ ), ou seja, aumentar a área bruta da seção do enrijecedor na parte comprimida da placa; enquanto a rigidez à flexão relativa da seção do enrijecedor ( parâmetro $\gamma$ ), e a rigidez à torção relativa da seção do enrijecedor (parâmetro $\theta$ ) são mantidos inalterados. Os enrijecedores na parte tracionada da placa não são ignorados, e os seus parâmetros $\gamma$, $\delta$ e $\theta$ são mantidos inalterados.

O Procedimento Proposto para calcular $\sigma_{\mathrm{cr}, \mathrm{p}}$ com EBPlate 2.01 para uma placa com enrijecedores longitudinais tem as seguintes vantagens:

a) o procedimento é geral, atende a qualquer que seja o número e a localização dos enrijecedores, o que evita as lacunas que existem entre as fórmulas da EN 1993-15:2006 para casos específicos;

b) os enrijecedores na parte tracionada não são ignorados, portanto o seu efeito vantajoso de rigidez à flexão é levado em conta;

c) a busca pelo primeiro modo global (com deformação global do enrijecedor) entre todos os modos de flambagem deixa de ser necessária, o que evita erros e valores inseguros.

\section{Casos estudados}

Foram estudados painéis enrijecidos, mais especificamente almas de viga com seção do tipo I enrijecidas com um ou dois enrijecedores longitudinais na região comprimida, submetidas a tensões normais longitudinais, $\sigma$, e tensões de cisalhamento, $\tau$, conforme mostra a Figura 5. 


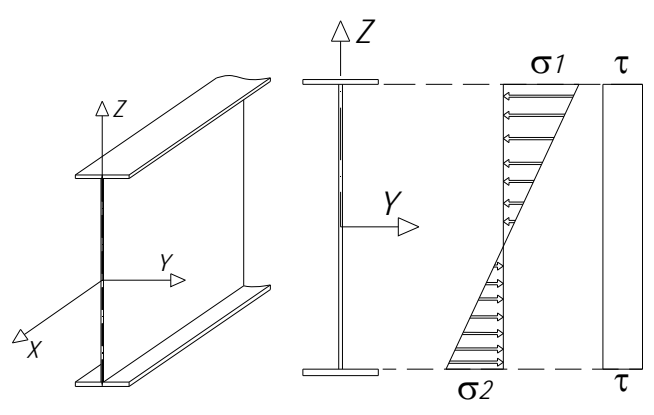

Figura 5 - Alma submetida às tensões normais longitudinais $(\sigma)$ e tensões de cisalhamento $(\tau)$.

Para todos os painéis estudados foram feitas as seguintes considerações:

a) resistência nominal ao escoamento do aço: $f_{y}=345 \mathrm{MPa}$;

b) módulo de elasticidade do aço: $\mathrm{E}_{\mathrm{a}}=200000 \mathrm{MPa}$;

c) coeficiente de Poisson do aço: $v=0,3$;

d) placa retangular simplesmente apoiada com comportamento isotrópico, carregada no seu plano, com espessura uniforme e tensões atuando ao longo das suas bordas;

e) enrijecedores longitudinais em seção retangular sólida, somente em um dos lados da alma da seção transversal do tipo l;

f) espessura da alma: variável.

As seções transversais do tipo I com almas enrijecidas têm as seguintes características, conforme mostram as Figura 6, Figura 7 e a Tabela 1.

Tabela 1 - Características das almas enrijecidas estudadas.

\begin{tabular}{c|c|c}
\hline Descrição & $\begin{array}{c}\text { Alma com um } \\
\text { enrijecedor }\end{array}$ & $\begin{array}{c}\text { Alma com dois } \\
\text { enrijecedores }\end{array}$ \\
\hline Dimensões das mesas & $300 \mathrm{~mm} \times 12,5 \mathrm{~mm}$ & $\begin{array}{c}300 \mathrm{~mm} \times 16 \mathrm{~mm} \text { (superior), } \\
700 \mathrm{~mm} \times 37,5 \mathrm{~mm} \text { (inferior) }\end{array}$ \\
\hline Largura do painel enrijecido & $3000 \mathrm{~mm}$ & $3500 \mathrm{~mm}$ \\
\hline Comprimento do painel enrijecido & $5000 \mathrm{~mm}$ & $5000 \mathrm{~mm}$ \\
\hline Razão de aspecto & $5000 / 3000=1,68$ & $5000 / 3500=1,43$ \\
\hline Dimensão do enrijecedor & $100 \mathrm{~mm} \times 12,5 \mathrm{~mm}$ & $140 \mathrm{~mm} \times 16 \mathrm{~mm}$ \\
\hline Posição do enrijecedor & $\mathrm{h}_{\mathrm{w}} / 4$ & $\mathrm{~h}_{\mathrm{w}} / 4, \mathrm{~h}_{\mathrm{w}} / 4$ \\
\hline Razão entre as tensões normais & $\sigma_{2} / \sigma_{1}=-1,0$ & $\sigma_{2} / \sigma_{1}=-0,60$ \\
\hline
\end{tabular}



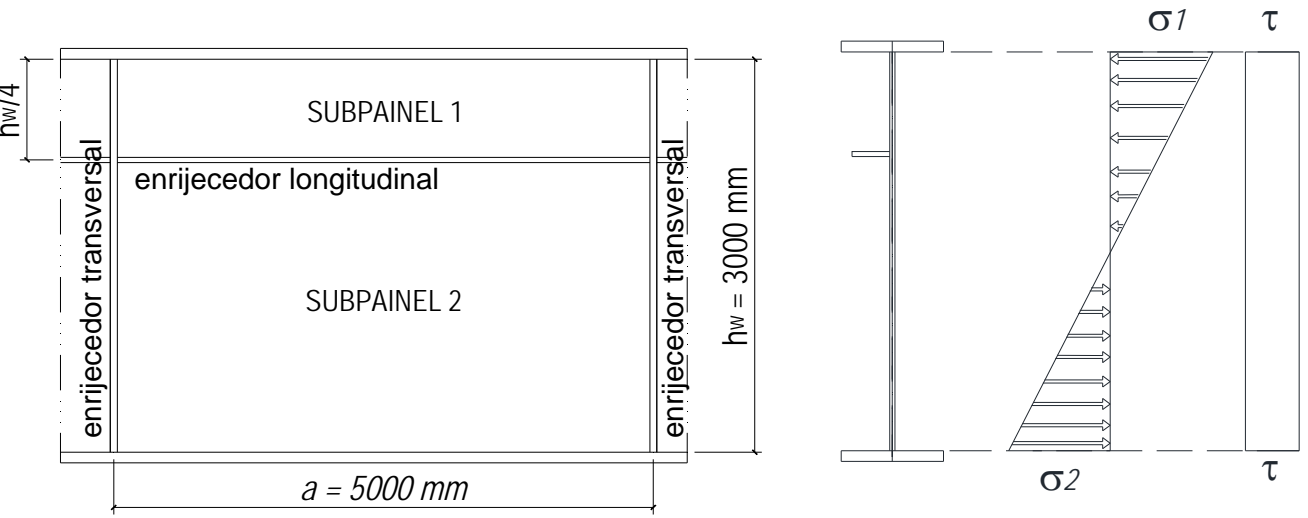

Figura 6 - Alma enrijecida com um enrijecedor longitudinal na região comprimida.
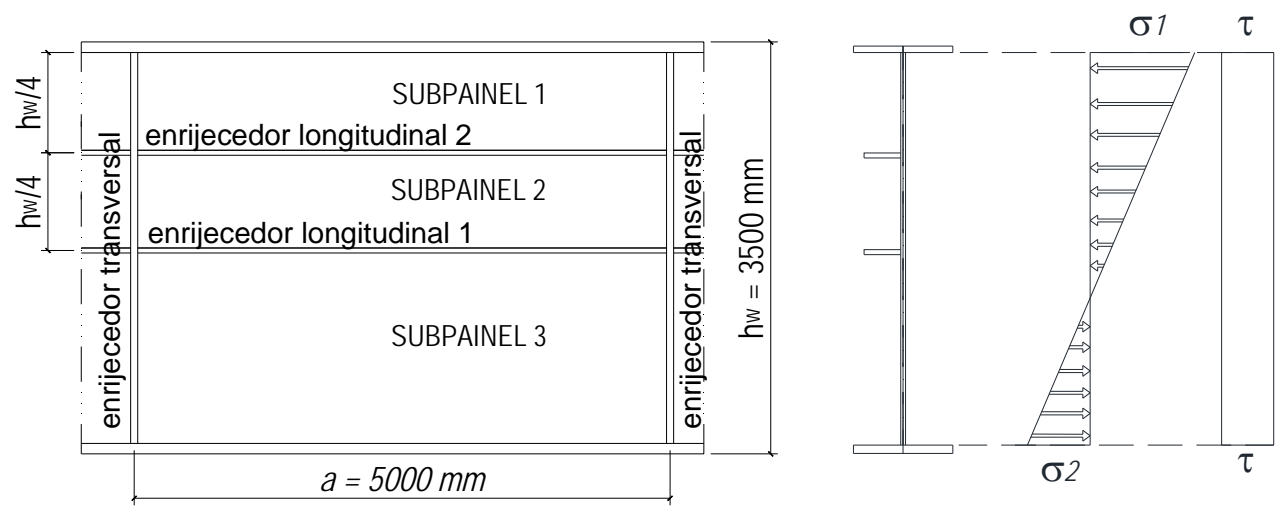

Figura 7 - Alma enrijecida com 2 enrijecedores longitudinais na região comprimida.

As tensões críticas globais de flambagem elástica dos casos estudados foram obtidas por meio do programa computacional EBPlate 2.01; e de uma planilha de cálculo desenvolvida com base na norma EN 1993-1-5:2006, no programa computacional Mathcad 2001 Professional, que é caracterizado por um ambiente de trabalho baseado em álgebra computacional.

\section{$5 \quad$ Análise dos resultados}

O modelo analítico do Anexo A da norma EN 1993-1-5:2006 para cálculo da tensão crítica de flambagem global devido às tensões normais, para o comportamento do Tipo Placa $\left(\sigma_{\mathrm{cr}, \mathrm{p}}\right)$ de uma placa com um único enrijecedor longitudinal na parte comprimida fornece resultados conservadores inferiores em até $25 \%$ aos valores fornecidos pelo Procedimento Proposto (Item 3.2) no programa computacional EBPlate 2.01. Entretanto, para enrijecedores rígidos $\left(\gamma>\gamma^{*}\right)$ o modelo analítico do Anexo A fornece resultados superestimados, maiores que os fornecidos pelo EBPlate 2.01, em até $18 \%$, conforme mostrado na Figura 8, na qual os valores no eixo horizontal representam os 
parâmetros $\gamma^{*}, \gamma$ e $t_{\mathrm{w}}$, e os valores no eixo vertical a tensão crítica de flambagem global devido às tensões normais, sendo que, o parâmetro variável foi a espessura da alma $\left(t_{w}\right)$. E ainda, o modelo analítico do Anexo A para cálculo da tensão crítica de flambagem global, de uma placa com dois enrijecedores longitudinais fornece resultados ainda mais conservadores inferiores aos valores fornecidos pelo Procedimento Proposto (Item 3.2) no programa EBPlate 2.01, em até $30 \%$. Por outro lado, apresentam valores favoráveis maiores que os valores fornecidos pelo programa EBPlate 2.01 , em até $14 \%$, para enrijecedores rígidos $\left(\gamma>\gamma^{*}\right)$, conforme mostrado na Figura 9, na qual os valores no eixo horizontal representam os parâmetros $\gamma^{*}, \gamma$ e $t_{w}$, e os valores no eixo vertical a tensão crítica de flambagem global devido às tensões normais, sendo que, o parâmetro variável foi a espessura da alma $\left(t_{w}\right)$.

Na Figura 8, observa-se que a partir da espessura de alma de $8,6 \mathrm{~mm}$ os enrijecedores são flexíveis $\left(\gamma<\gamma^{*}\right)$, e as curvas se cruzam entre as espessuras de alma de 8,6 e 8,9 $\mathrm{mm}$, na transição de enrijecedor rígido para flexível.

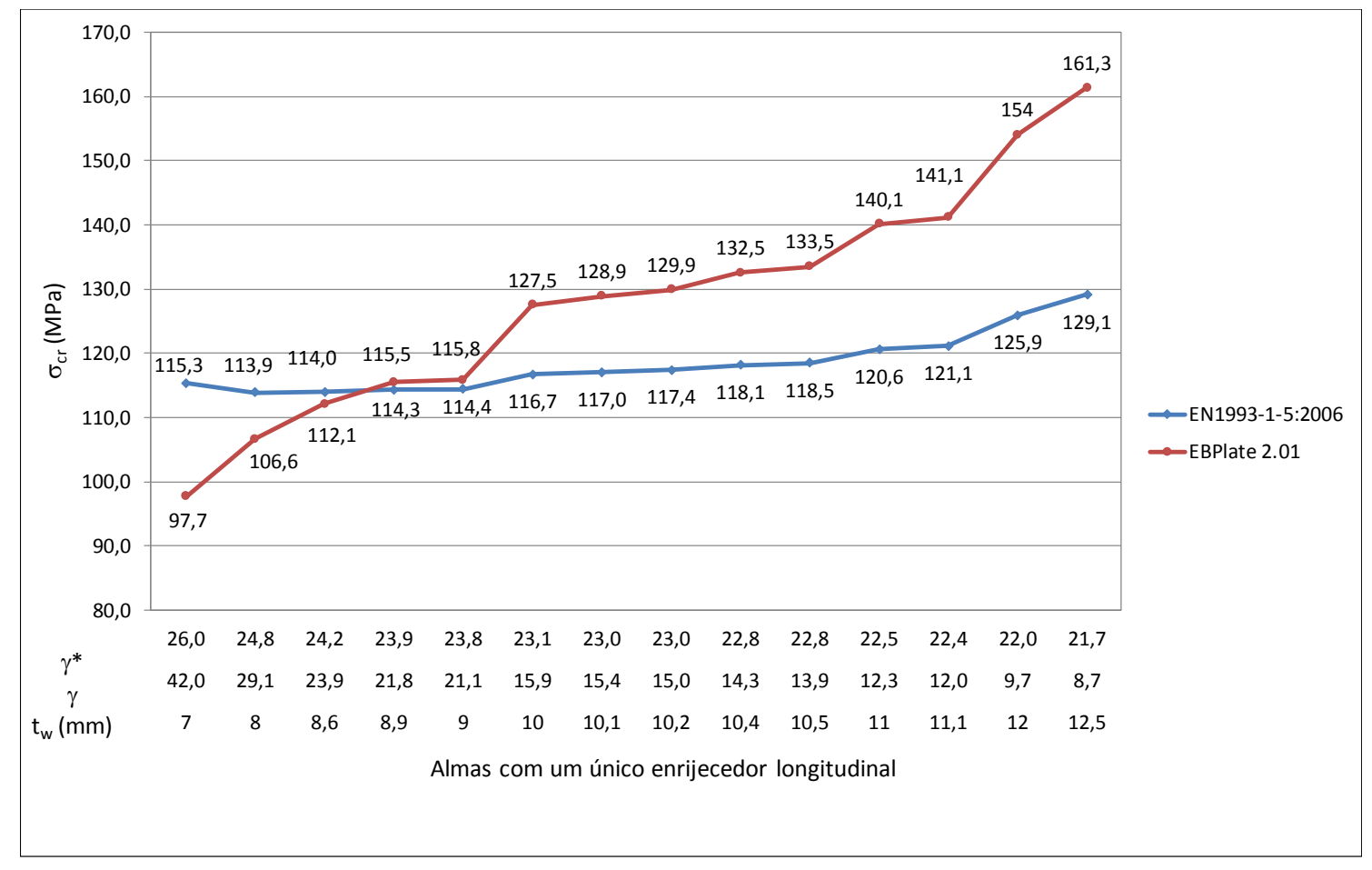

Figura 8 - Tensões críticas globais devido às tensões normais - Almas com um único enrijecedor longitudinal - EN1993-1-5:2006 versus EBPlate 2.01. 


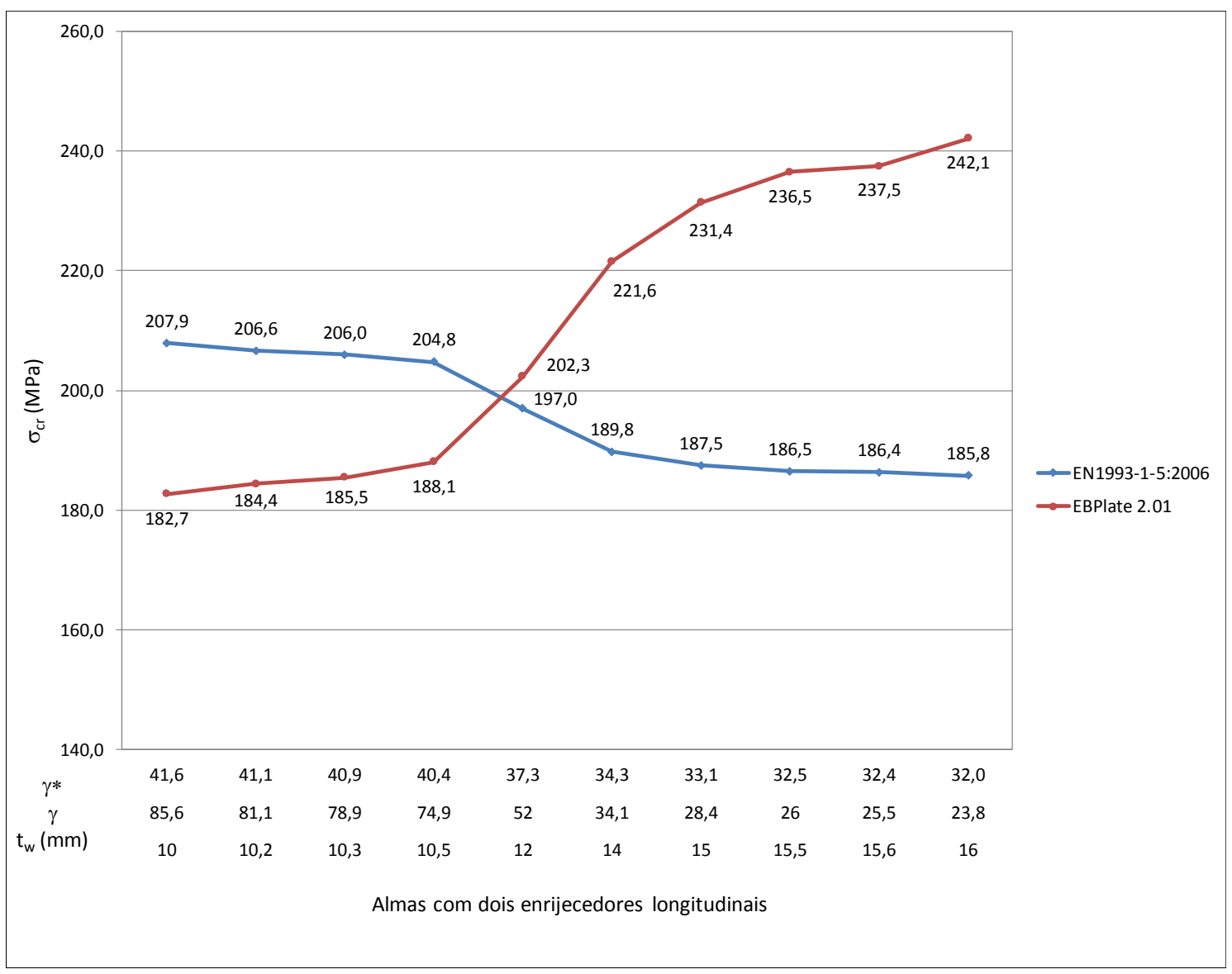

Figura 9 - Tensões críticas globais devido às tensões normais - Almas com dois enrijecedores longitudinais - EN1993-1-5:2006 versus EBPlate 2.01.

Sendo assim, para as espessuras de alma entre 8 e $8,9 \mathrm{~mm}$ o valor da rigidez à flexão relativa $(\gamma)$ se aproxima ao da rigidez relativa ótima $\left(\gamma^{*}\right)$, e a tensão crítica calculada pelo EBPlate 2.01 se aproxima da calculada pelo Anexo A da EN1993-1-5:2006.

Na Figura 9, observa-se que para espessura de alma de até $12 \mathrm{~mm}$ os enrijecedores são rígidos $\left(\gamma>\gamma^{*}\right)$, e as curvas se cruzam para espessuras de alma entre 10,5 e $12 \mathrm{~mm}$, na iminência da transição de enrijecedor rígido para flexível que ocorre para as espessuras de alma entre 12 e $14 \mathrm{~mm}$. Portanto, para as espessuras de alma entre 10,5 e $14 \mathrm{~mm}$ o valor da rigidez à flexão relativa $(\gamma)$ se aproxima ao da rigidez relativa ótima $\left(\gamma^{*}\right)$, e a tensão crítica calculada pelo EBPlate 2.01 se aproxima da calculada pelo Anexo A da EN1993-1-5:2006.

As almas estudadas têm enrijecedores localizados próximos à mesa na parte comprimida, sendo assim, o modelo analítico simplificado conforme o Anexo A da norma EN 1993-1-5:2006 forneceu resultados conservadores para enrijecedores 
flexíveis, conforme mostram as Figura 8 e Figura 9. Além disso, o fato do modelo analítico do Anexo A da norma EN 1993-1-5:2006 desconsiderar a rigidez torcional do enrijecedor, e o programa EBPlate 2.01 levar em conta este parâmetro, contribuiu para que no caso dos enrijecedores flexíveis, os valores obtidos pelo EBPlate 2.01 fossem maiores que os calculados pelo Anexo A da norma EN 1993-1-5:2006, conforme mostram as Figura 8 e Figura 9.

Galéa e Martin (2007) realizaram um estudo com várias configurações de placas enrijecidas com um único enrijecedor, variando a localização do enrijecedor e a distribuição das tensões axiais, e de forma geral obtiveram resultados conservadores utilizando o modelo analítico do Anexo A da EN 1993-1- 5:2006 para o cálculo da tensão crítica de flambagem, sendo inferiores em até $20 \%$ em comparação com o valor dado pelo método proposto usando o EBPlate 2.01. Entretanto, obtiveram resultados favoráveis superiores em até $10 \%$ para enrijecedores muito rígidos. Além disso, conforme Galéa e Martin (2010), o modelo analítico do Anexo A para uma placa enrijecida com dois enrijecedores é muito conservador, e que os desvios dos resultados teóricos esperados podem chegar a $30 \%$.

Para cálculo da tensão crítica de flambagem global devido às tensões de cisalhamento, para almas com um único enrijecedor longitudinal, o modelo analítico do Anexo $\mathrm{A}$ da norma EN 1993-1-5:2006 fornece resultados próximos aos resultados obtidos no programa EBPlate 2.01, sendo os valores obtidos pelo Anexo A inferiores em até $16 \%$ aos obtidos pelo EBPlate 2.01, conforme mostrado na Figura 10. Porém, para almas com dois enrijecedores longitudinais, os valores obtidos pelo Anexo A são inferiores em até 98\% aos obtidos pelo EBPlate 2.01, conforme mostrado na Figura 11.

\section{Conclusões}

Na comparação entre os valores obtidos de tensões críticas globais de flambagem elástica devido às tensões normais, observa-se que no caso de placa enrijecida com enrijecedores flexíveis $\left(\gamma<\gamma^{*}\right)$ os valores calculados pelo Anexo A da norma EN 19931-5:2006 são conservadores em relação aos calculados pelo Método Proposto (Item 3.2) no programa EBPlate 2.01. Os valores calculados pelo Anexo A são inferiores aos valores obtidos no EBPlate 2.01 , em até $25 \%$ para placa com um único enrijecedor longitudinal, 
e em até $30 \%$ para placa com dois enrijecedores longitudinais. Entretanto, para enrijecedores rígidos $\left(\gamma>\gamma^{*}\right)$, os valores obtidos pelo Anexo A são superiores aos obtidos no EBPlate 2.01, em até $18 \%$ para placa com um único enrijecedor longitudinal, e em até $14 \%$ para placa com dois enrijecedores longitudinais.

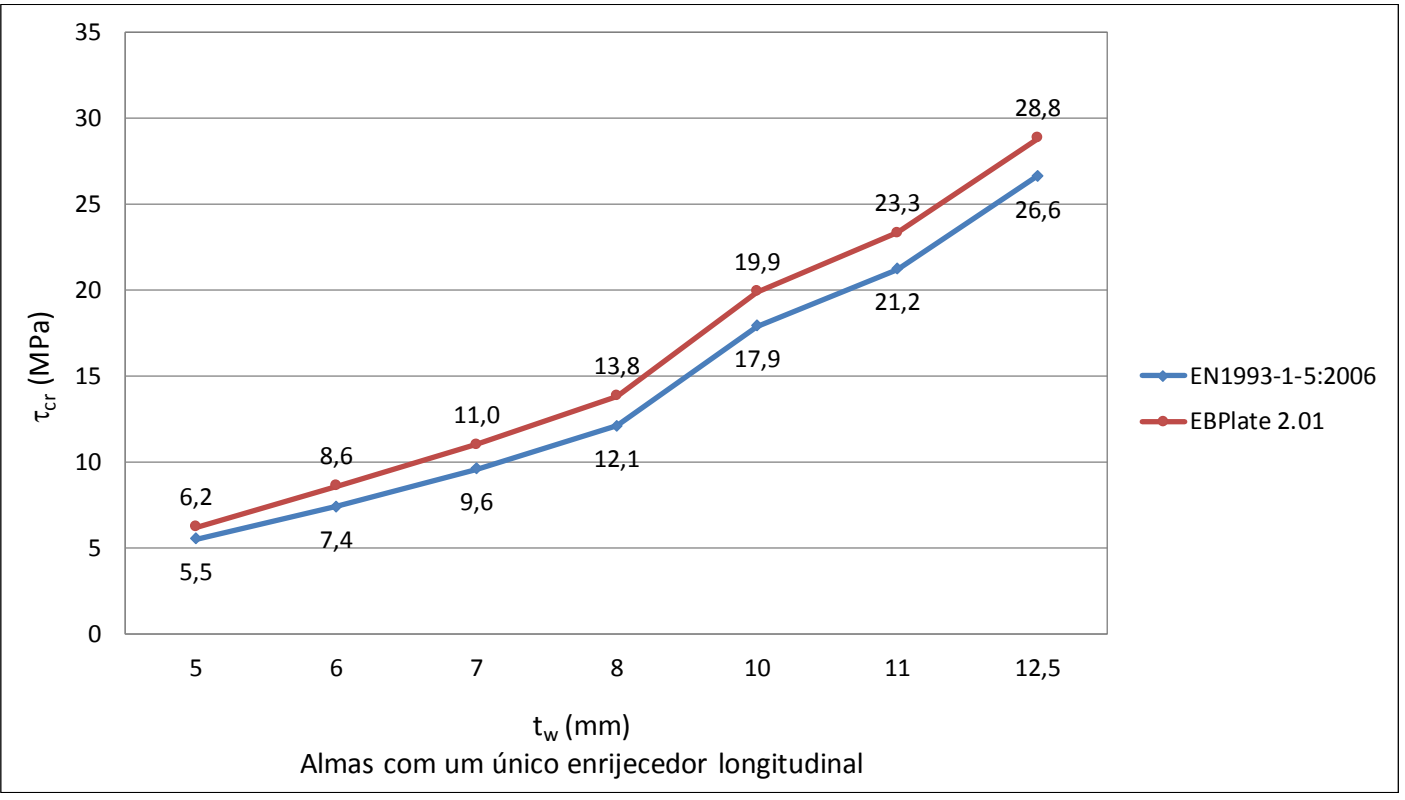

Figura 10 - Tensões críticas globais devido às tensões de cisalhamento - Almas com um único enrijecedor longitudinal - EN1993-1-5:2006 versus EBPlate 2.01.

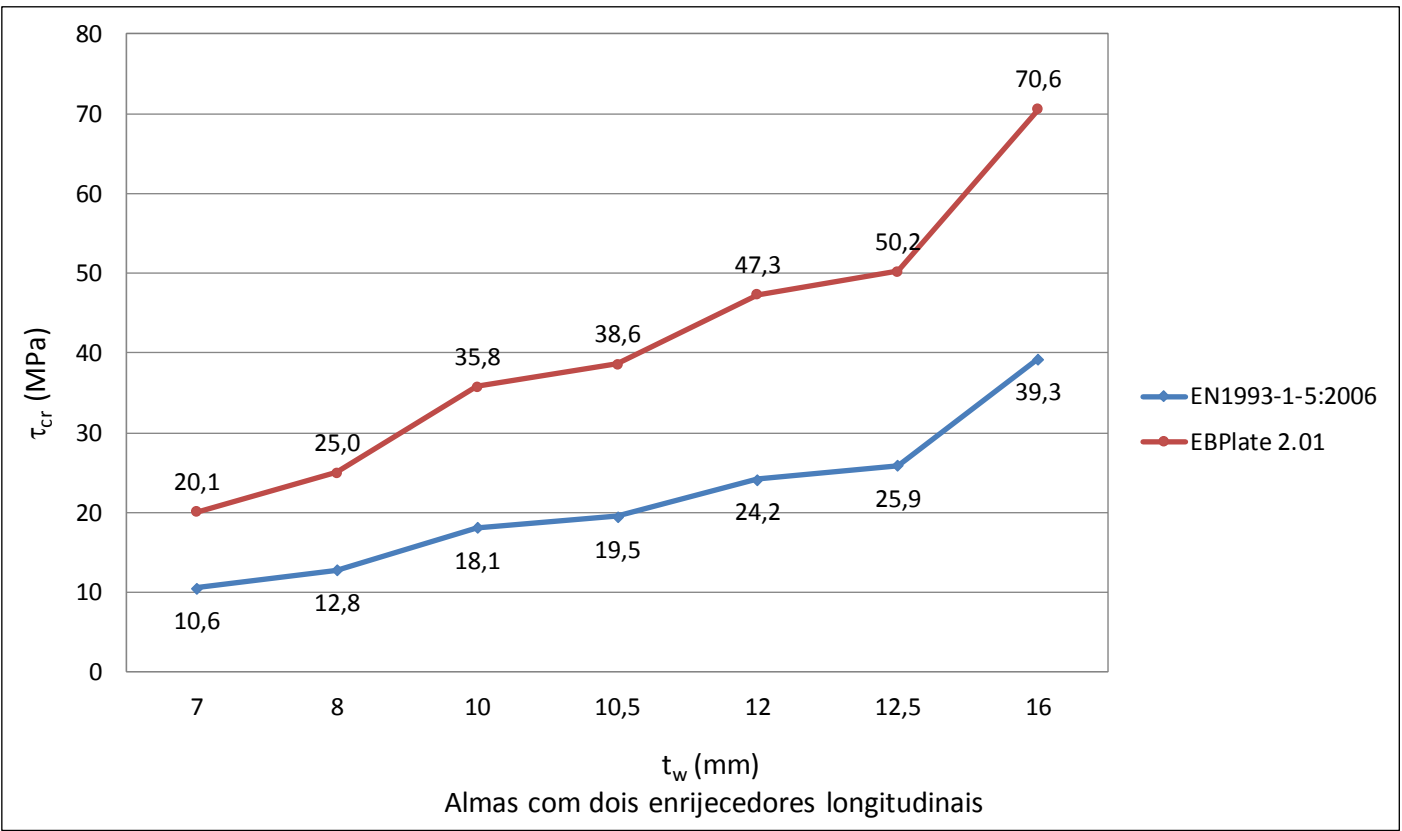

Figura 11 - Tensões críticas globais devido às tensões de cisalhamento - Almas com dois enrijecedores longitudinais - EN1993-1-5:2006 versus EBPlate 2.01. 
O fato das tensões críticas globais de flambagem elástica devido às tensões normais calculados pelo Anexo A da norma EN 1993-1-5:2006 serem superiores às calculadas pelo EBPlate 2.01 para enrijecedores rígidos, e por outro lado serem inferiores para enrijecedores flexíveis, ocorre porque o Anexo A utiliza modelos analíticos simplificados, visto que tanto o método proposto pelo EBPlate 2.01 quanto o Anexo A foram estabelecidos considerando que a flambagem Tipo Placa corresponde a um modo de flambagem resultante da flexão dos enrijecedores longitudinais fora do plano da placa, ou seja, flambagem global do painel enrijecido sem qualquer flambagem local nos subpainéis. Sendo assim, como a norma fornece fórmulas para casos específicos, porém não sugere um método geral, isto é, para qualquer que seja o número e a localização dos enrijecedores longitudinais e, além disso, fornece valores favoráveis para o caso de placas com enrijecedores rígidos, o uso do programa EBPlate 2.01 torna-se viável.

Na obtenção das tensões críticas de cisalhamento, para almas com um único enrijecedor longitudinal, o modelo analítico do Anexo A da norma EN 1993-1-5:2006 fornece resultados próximos aos resultados obtidos no programa EBPlate 2.01, sendo os valores obtidos pelo Anexo A inferiores em até $16 \%$ aos obtidos pelo EBPlate 2.01. Entretanto, para almas com dois enrijecedores longitudinais, os resultados são distantes entre si, sendo os valores obtidos pelo Anexo A inferiores em até $98 \%$ aos obtidos pelo EBPlate 2.01 .

Conclui-se que os resultados do programa EBPlate possam representar melhor os valores de tensão crítica, uma vez que o programa EBPlate 2.01 pode ser utilizado para casos gerais, e o Anexo A da norma EN 1993-1-5:2006 utiliza modelos analíticos simplificados e para casos específicos.

\section{Agradecimentos}

Os autores agradecem o apoio concedido pela CAPES (Coordenação de Aperfeiçoamento de Pessoal de Nível Superior), CNPq (Conselho Nacional de Desenvolvimento Científico e Tecnológico), FAPEMIG (Fundação de Amparo à Pesquisa do Estado de Minas Gerais) e UFMG (Universidade Federal de Minas Gerais). 


\section{Referências bibliográficas}

ANSYS, C. F. X. Release 11.0. ANSYS CFX-Solver Theory Guide, ANSYS, 2006.

BARBOSA, D.A.; CALDAS, R.B. Estudo Comparativo da Tensão Crítica Elástica de Flambagem de Chapas Enrijecidas em Aço. In: IX Congresso Brasileiro de Pontes e Estruturas. Rio de Janeiro: 18 a 20 de maio, 2016.

BARBOSA, D.A. Estudo de almas de vigas de aço enrijecidas longitudinalmente. 2016. $300 f$. Dissertação (Mestrado) - Escola de Engenharia, Universidade Federal de Minas Gerais, 2016.

BEG, D.; KUHLMANN, U.; DAVAINE, L.; BRAUN, B. Design of plated structures. ECCS Eurocode design manual. Publication by Ernst \& Sohn, 2010.

CTICM; RFS; COMBRI. EBPlate: elastic buckling of plates, Software Developed by Centre Technique Industriel de la Construction Metallique (CTICM) in the Frame of the ComBri Project, RFCS Contract n ${ }^{\circ}$ RFS-CR-03018, 2006. Disponível em: www.cticm.com.

DA SILVA, L. S.; GERVÁSIO, H. Manual de dimensionamento de estruturas metálicas: métodos avançados. CMM, Mem Martins (in Portuguese), 2007.

EUROPEAN COMMITTEE FOR STANDARDIZATION - CEN. EN 1993-1-5. Eurocode 3 - Design of steel structures - part 1-5: general rules - plated structural elements. 2006.

GALÉA, Y., MARTIN, P. Presentation Manual of EBPlate. Liege: CTICM - Centre Technique Industriel de la Construction Métallique, 2006, 48 str.

GALÉA, Y., MARTIN, P. Plate type behaviour. Use of EBPlate to calculate $\sigma_{c r, p}$. CTICM Document no. 7.054-03. 2007.JOHANSSON, B.; MAQUOI, R.; SEDLACEK, G.; MÜLLER, C.; BEG, D. Commentary and worked examples to EN 1993-1-5: Plated structural elements. Joint report JRC-ECCS, 2007.

GALÉA, Y.; MARTIN, P. O. Longitudinally stiffened plates in Eurocode 3: Calculation of the global critical buckling stress. Journal of Constructional Steel Research, v. 66, n. 11, p. 13451353, 2010.

LEBET, J.P; HIRT, M.A. Steel bridges: conceptual and structural design of steel and steelconcrete composite bridges. CRC Press, 2013.

PAVLOVČIČ, L.; BEG, D.; KUHLMANN, U. Shear resistance of longitudinally stiffened panelsPart 2: Numerical parametric study. Journal of Constructional Steel Research, v. 63, n. 3, p. 351-364, 2007.

SKALOUD, M. Optimum rigidity of stiffeners of webs and flanges. Plated Structures, Stability and Strength, p. 103-133, 1983.

VAYAS, I.; ILIOPOULOS, A. Design of steel-concrete composite bridges to eurocodes. CRC Press, 2013. 